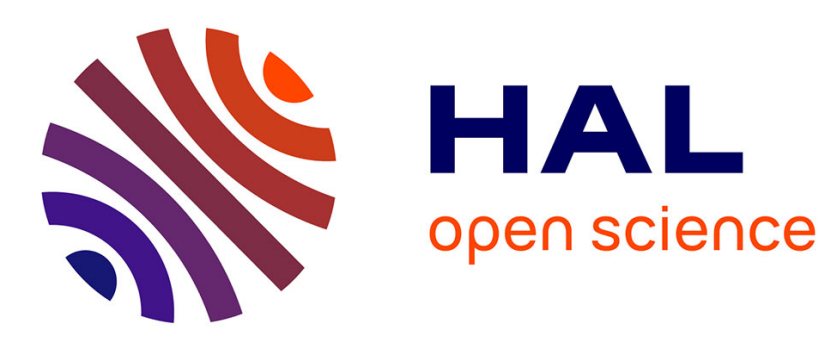

\title{
ANALYSIS AND DESIGN OF A HIGH-GAIN ANTENNA BASED ON METALLIC CRYSTALS
}

Halim Boutayeb, Tayeb Denidni

\section{To cite this version:}

Halim Boutayeb, Tayeb Denidni. ANALYSIS AND DESIGN OF A HIGH-GAIN ANTENNA BASED ON METALLIC CRYSTALS. Journal of Electromagnetic Waves and Applications, 2006, 20 (5), pp. 599-614. 10.1163/156939306776137755 . hal-00149260

\section{HAL Id: hal-00149260 https://hal.science/hal-00149260}

Submitted on 25 May 2007

HAL is a multi-disciplinary open access archive for the deposit and dissemination of scientific research documents, whether they are published or not. The documents may come from teaching and research institutions in France or abroad, or from public or private research centers.
L'archive ouverte pluridisciplinaire HAL, est destinée au dépôt et à la diffusion de documents scientifiques de niveau recherche, publiés ou non, émanant des établissements d'enseignement et de recherche français ou étrangers, des laboratoires publics ou privés. 


\title{
ANALYSIS AND DESIGN OF A HIGH-GAIN ANTENNA BASED ON METALLIC CRYSTALS
}

\author{
H. Boutayeb and T.A. Denidni \\ INRS-EMT, 800 rue de la Gauchetiere, Montreal, Quebec H5A 1K6, \\ Canada.
}

\begin{abstract}
In this paper, a new high-gain antenna made from a monopole embedded in a crystal, also called Electromagnetic Bandgap (EBG) material, with metallic wires and without defect is described. To design the antenna, a model is proposed, using the crystal as a Fabry-Perot cavity constructed of multiple Partially Reflecting Surfaces (PRSs). Frequency and pattern responses of the EBG structure excited by electromagnetic waves from its interior are used to analyze the antenna performance. To validate the proposed approach, numerical simulations using the Finite Difference Time Domain (FDTD) method were carried out, and an antenna prototype was fabricated and tested. The radiation patterns obtained from measurements and simulations show an excellent directivity performance and give a good agreement between measured, simulated and predicted results. With the proposed design, a more than $19 \mathrm{dBi}$ gain is achieved across the matching band.
\end{abstract}

\section{INTRODUCTION.}

Electromagnetic bandgap (EBG) materials, also known as photonic crystals [1], have been the subject of intensive research in the past few years. Potential applications have been suggested in microwave and antenna domains, such as suppressing surface waves [2], [3], creating controllable beams [4], [5], and designing high-gain antennas with a single feed [6]-[16]. This paper presents the analysis and results of a new high-gain antenna based on a metallic crystal.

High-gain, low-cost antennas using a single feed and based on EBG materials have an attractive interest for several wireless communication systems such as high-speed Wireless Local Area Networks (WLANs), satellite receiver systems, and various point-to-point links. Their single-feed system reduces the feed complexity compared to feeding 
networks used in conventional antenna arrays. Furthermore, EBGantennas are typically more compact than parabolic reflector antennas. Recently, various techniques have been proposed to design directive antennas formed by a dipole embedded inside a Fabry-Perot cavity. In this context, a relation between the half power beamwidth and the quality factor of the cavity has been proposed and validated numerically [6], and the directivity improvement has been suggested based on past research in optical physics [7]. Recently, in [8], analytical expressions and experimental results have been proposed for the directivity of antennas based on a Fabry-Perot cavity at different frequencies. In [9], the authors have presented an antenna based on a dielectric EBG structure with a defect, which consists of a FabryPerot cavity between a patch antenna and the EBG structure. The defect generates the radiation of localized modes in the frequency bandgaps. The same configuration has been revisited in [10], where a method based on the Fourier transform has been proposed to obtain the properties of the EBG structure in the angular domain and then to predict the radiation pattern of an EBG antenna. This antenna can be seen as a dielectric leaky-wave antenna (LWA) [11]. It has been shown that the fundamental principle of operation of a LWA is due to the excitation of leaky modes in the structure [12], and a further examination of the structure has been given in [13]. In addition, a simple model has been proposed and analyzed using a transverse equivalent network [14].

Other studies of a dipole or a monopole embedded inside a periodic structure without defect have been reported in [15], [16], where the dispersion diagram of the crystal and the the effective refractive index have been used to explain the directivity improvement, and numerical and experimental results showing high directivity have also been presented. However, the return loss of the antenna is not low enough. In [17], a study of the input impedance of an EBG antenna fed by a monopole has been presented, and a low return loss has been achieved.

Another method for producing a high-gain antenna has been introduced in the 50's [18]. This technique uses a PRS to introduce leaky wave and beamforming effects when it is placed in front of a grounded waveguide aperture. A ray theory has been proposed, which shows that the directivity of the antenna increases when the reflectivity of the PRS increases. This type of antenna has been improved recently [19], where the PRS is optimized to enlarge the antenna bandwidth. Furthermore, experimental results have been presented for the case of multiple PRSs in front of the waveguide [20].

To analyze rectangular crystals, various methods have been proposed 
for calculating the scattering of the structures, e.g. the rigorous scattering matrix method [21], and the generalized scattering matrix method with a cascading approach [22], where the periodic structure is made from the cascading of multiple layers of PRSs, also called Frequency Selective Surfaces (FSSs) [23]. These methods are rigorous but they are typically time-consuming.

In this paper, a modeling method based on a spectral plane-wave generalized-ray analysis with a cascading process and the FabryPerot model is presented to predict the characteristics of a high-gain antenna based on a crystal without defect. The proposed method does not consider the higher Floquet modes interactions between PRSs, but it reduces considerably the computational time compared to the preceding methods and it is well suited for the design process of the proposed EBG antenna. Using this method, a new directive antenna was designed, fabricated and tested.

\section{ANALYSIS}

In order to predict the antenna performance, the main properties of a 2D periodic crystal were studied in the frequency and angular domains. One can characterize an EBG material by its band structure when it is infinite in all directions of propagation and by its transmission and reflection coefficients when it is illuminated by plane waves from the exterior and it is finite in the direction of propagation. Another possible characterization of the EBG material is obtained from its response when it is illuminated by plane waves from its interior. In this study, a TM-wave excitation is considered. The band structure of the proposed EBG material and the characterization of the EBG material excited internally are described in the following subsections.

\subsection{Band Structure}

A 2-D EBG material made of infinite metallic wires is considered as shown in Figure 1(a). $P_{x}$ and $P_{y}$ are the periods of the structure in the $x$ and $y$ directions and $d$ is the diameter of the wires. Figure 1(b) presents the irreducible Brillouin zone of the rectangular lattice [1]. Figure 2 presents the band structure of the metallic crystal, which was computed with Ansoft High Frequency Structure Simulator (HFSS) [24]. From these curves, it can be observed that a bandgap (stopband) is obtained at low frequencies until $2.6 \mathrm{GHz}$. In this band, no propagation of the electromagnetic wave is possible, then for the proposed application, the EBG material will be used at the propagating band. In the next section, the properties of this EBG material are 


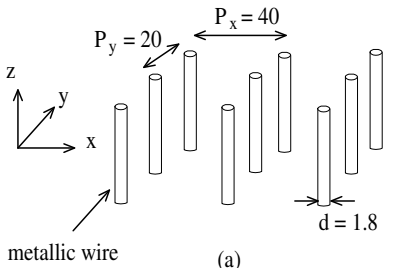

(a)

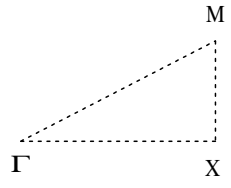

(b)

Figure 1. (a) Infinite 2-D periodic structure of continuous metallic wires in air (dimensions in $\mathrm{mm}$ ) (b) Irreducible Brillouin zone of the rectangular lattice with corners labelled $\Gamma, \mathrm{X}, \mathrm{M}$.

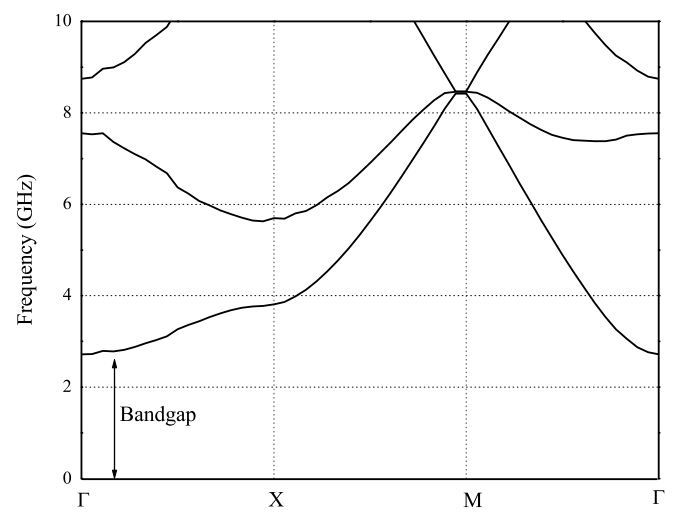

Figure 2. Band diagram for the rectangular 2-D periodic structure $\left(P_{x}=40 \mathrm{~mm}, P_{y}=20 \mathrm{~mm}\right.$ and $\left.d=1.8 \mathrm{~mm}\right)$.

analyzed when it is excited from its inside.

\subsection{Internally excited EBG material}

Figure 3 shows the model of the EBG structure excited from its inside. The EBG structure is now finite in $x$-direction, and it is composed of six infinite rows of metallic wires. The source is located at the center. The rays going throw the structure at $\theta$ direction are considered, and each row acts as a Partially Reflecting Surface (PRS) for these rays. The EBG structure is considered as a set of $n$ PRS(s) on each side of the source. Each PRS is characterized by its complex transmission and 
reflection coefficients: $t$ and $r$, respectively. To investigate the property of the EBG material, the Fabry-Perot cavity model [25] presented in Fig. 4 is used, where the $n$ PRS(s) are replaced by one PRS with the transmission and reflection coefficients $t_{n}$ and $r_{n}$, respectively $\left(t_{1}=t\right.$, $\left.r_{1}=r\right)$.

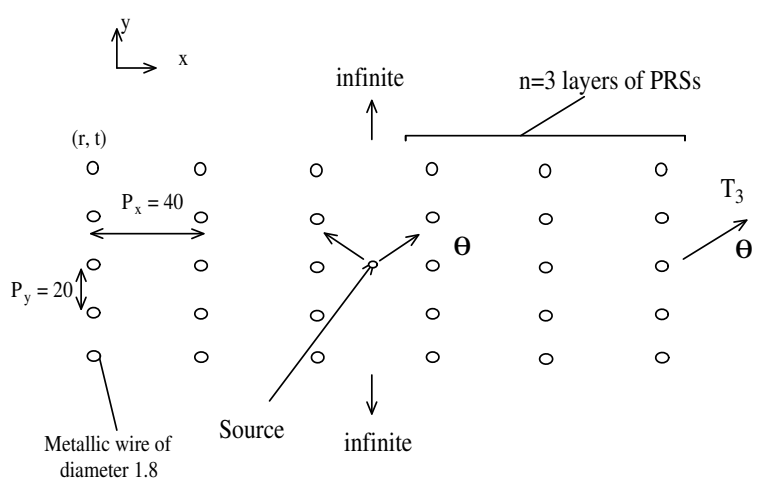

Figure 3. EBG structure excited by an omnidirectional source (dimensions in $\mathrm{mm}$ ).

Note that, usually, in the Fabry-Perot interferometer, the source is outside the Fabry-Perot cavity [25], [26], whereas here the source is placed inside the cavity.

The variable $T_{n}$ characterizes the entire structure, and it is obtained by calculating the sum of all transmitted rays (Fig. 4). In Fig. 4, the semi-axis $X$ is used for the phase reference. The sum of all rays gives the following expression for the total transmitted amplitude $T_{n}$

$$
\begin{gathered}
T_{n}(f, \theta)=t_{n}(f, \theta) \sum_{i=0}^{\infty} r_{n}(f, \theta)^{i} e^{j k(2 i+1) P_{x} / 2 \tan \theta \sin \theta-\frac{j k(2 i+1) P_{x}}{2 \cos \theta}} \\
=\frac{t_{n}(f, \theta) e^{-j k P_{x} \cos (\theta) / 2}}{1-r_{n}(f, \theta) e^{-j k P_{x} \cos (\theta)}} .
\end{gathered}
$$

To obtain $t_{n}$ and $r_{n}$, the schematic presented in Fig. 5 is used, where the semi-axis $X^{\prime}$ is used for the phase reference for $t_{n}$ and the ray 0 in the left is used for the phase reference for $r_{n}$. These coefficients are written as functions of $t, r, t_{n-1}$ and $r_{n-1}$, where $t_{n-1}$ and $r_{n-1}$ are the coefficients of the structure composed of $(n-1)$ PRS(s). The sum of the transmitted rays gives the following iterative expressions for $t_{n}$ and $r_{n}$

$$
t_{n}(f, \theta)=\frac{t_{n-1}(f, \theta) t(f, \theta) e^{-j k P_{x} \cos (\theta)}}{1-r_{n-1}(f, \theta) r(f, \theta) e^{-j 2 k P_{x} \cos (\theta)}}
$$




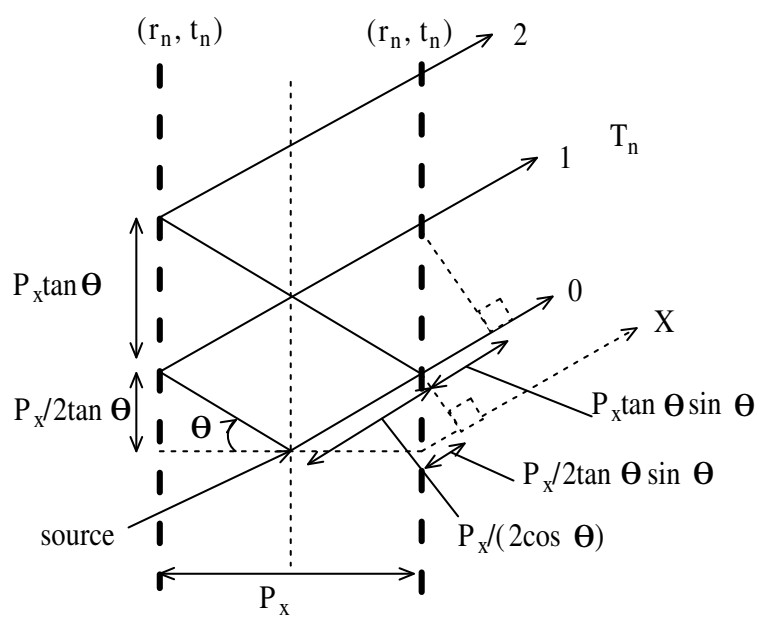

Figure 4. Fabry-Perot cavity model for the calculation of the EBG structure response.

and

$$
r_{n}(f, \theta)=r_{n-1}(f, \theta)+\frac{t_{n-1}(f, \theta)^{2} t(f, \theta) e^{-j k 2 P_{x} \cos (\theta)}}{1-r_{n-1}(f, \theta) r(f, \theta) e^{-j 2 k P_{x} \cos (\theta)}} .
$$

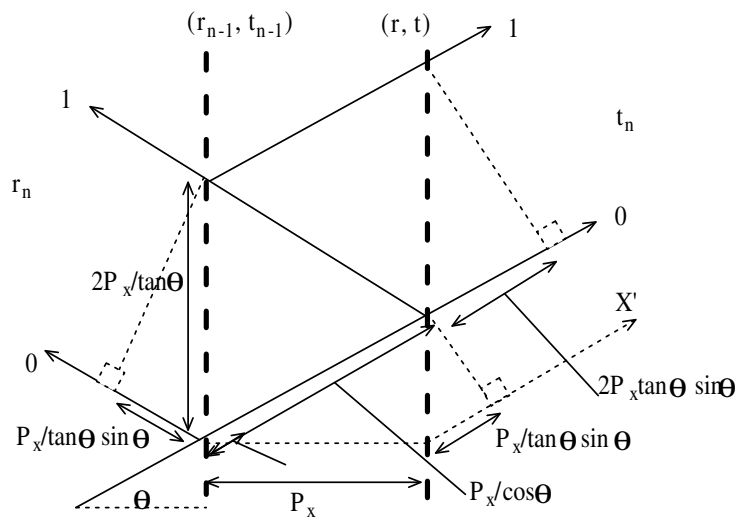

Figure 5. Calculation of $t_{n}$ and $r_{n}$ coefficients from $t_{n-1}$ and $r_{n-1}$.

In this work, $t$ and $r$ coefficients are computed rigourously using a 
Finite Difference Time Domain (FDTD) code, where a thin mesh $(\triangle=\operatorname{Period} / 80)$ is used. As an approximation, the dependance of $t$ and $r$ on the incidence angle is not taking into account in Eqs. (1)(3). This approximation is valid when $P_{x}$ is sufficiently small compared to $\lambda[18]$.

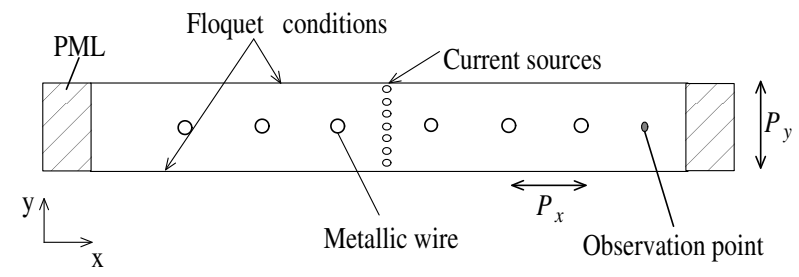

(a)

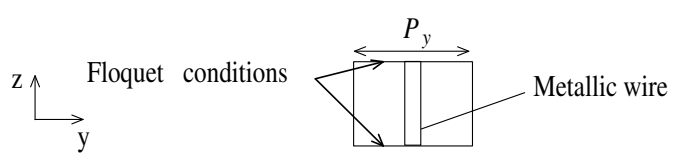

(b)

Figure 6. Schematic for the calculation of $T_{n}(f, 0)(n=3)$ in the FDTD code (a) xoy plane view (b) yz plane view.

To validate the preceding relations for the $T_{n}$ variable at the normal incidence $\left(\theta=0^{\circ}\right)$, direct simulations with the FDTD code were carried out. Figure 6 shows the scheme used in the FDTD code to calculate $T_{3}$ at $\theta=0^{\circ}$. In the FDTD code, the boundaries in the $x y$ and $z x$ planes satisfy Floquet's theorem since the structure is infinite in the two dimensions. Each boundary in the $y z$ plane uses the Perfect Matched Layers (PML) technique [27] to model the free space. The wires were modeled using a thin wire formalism [28], the plane wave excitation were modeled with a plane of current sources, and an observation point were considered to compute the transverse electric field. Two simulations were carried out: one with the structure and another without the structure for normalization. Figure 7 presents the coefficient $\left|T_{3}\left(f, 0^{\circ}\right)\right|$ obtained with the FDTD method and calculated with Eqs. (1)-(3). A good agreement is observed between the results obtained by the current method and those computed by the FDTD method.

Figure 8 shows $\left|T_{n}(f, 0)\right|$ obtained for different values of $n$. From these curves, $\left|T_{n}(f, 0)\right|$ presents a stopband in low frequencies and a passband with higher-values peaks, where the number of peaks is 


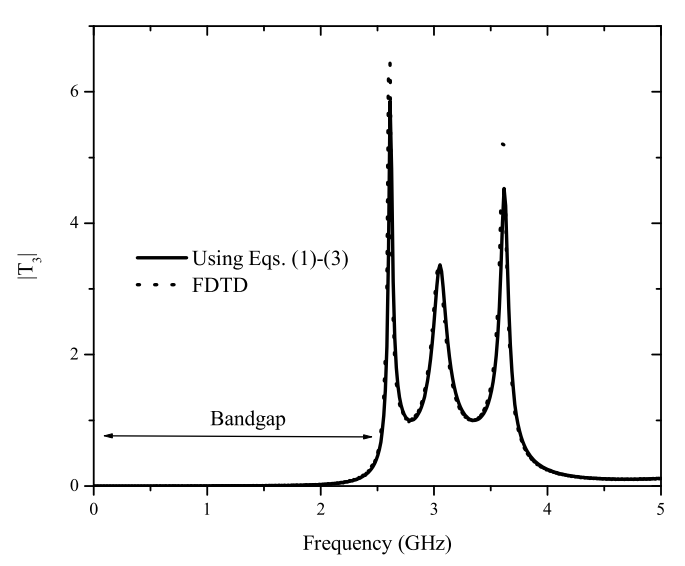

Figure 7. $\left|T_{3}\left(f, 0^{\circ}\right)\right|$ versus frequency calculated using Eqs. (1)-(3) and calculated directly with the FDTD method.

correlated to $n$. The reason of a strength of $\left|T_{n}\right|$ greater than one is that the cavity modifies the matching of the plane-wave source, which is not initially matched to free space, and then the power supplied outside the cavity, at resonance, is greater than the power supplied by the source alone. From this, the strength of $\left|T_{n}\right|$ is not a direct evaluation of the directivity of the EBG-antenna. However, the halfpower beam-width and then the directivity of a directive antenna based on a Fabry-Perot cavity can be evaluated by using this coefficient as has been demonstrated recently in [8].

Figure 9 presents the $\left|T_{3}\right|$ variables versus frequency, calculated using Eqs. (1)-(3), at $\theta=0^{\circ}$ and $\theta=30^{\circ}$. The first resonance frequency $f_{0}$ of $\left|T_{3}\right|$ at $\theta=0^{\circ}$ is about $2.6 \mathrm{GHz}$.

As referring to Fig. 9, when the angle $\theta$ increases, the level of $\left|T_{3}\right|$ at $f_{0}$ decreases, and for sufficiently large angle, this frequency belongs to the first stop-band of $\left|T_{3}\right|$. Then, the crystal acts as a spacial filter. To illustrate this spacial filtering, Fig. 10 presents $\left|T_{3}\right|$ versus the incidence angle at three frequencies $f_{0}, f_{1}$, and $f_{2}$ (these are the first, the second and the third resonance frequencies of $\left|T_{3}\left(f, 0^{\circ}\right)\right|$, respectively). These curves can be interpreted as the radiation patterns of the structure. At the frequency $f=f_{0}$, there are two directive beams at the normal with a half power beamwidth equals to $11.5^{\circ}$. The directivity is maximum near the frequency $f_{0}$. At frequencies greater than $f_{0}$, lobes appear in other directions as illustrated in Fig. 10. To design a directive antenna, 


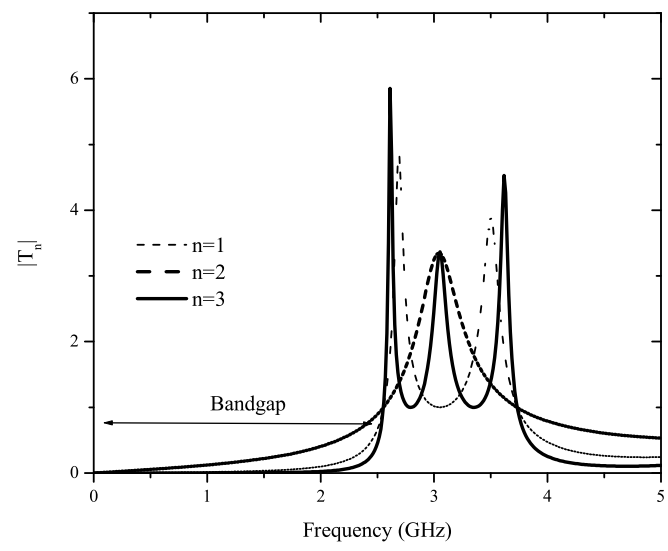

Figure 8. $\left|T_{n}\left(f, 0^{\circ}\right)\right|$ for different number of layers $n$ on each side of the source.

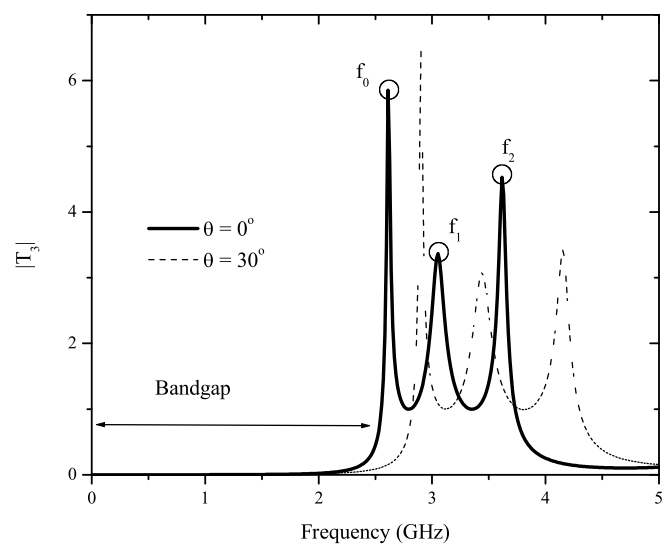

Figure 9. $\left|T_{n}\right|$ versus frequency at $\theta=0^{\circ}$ and $\theta=30^{\circ}$, of the EBG structure composed of $n=3$ PRSs on each side of the source.

the frequency $f_{0}$ is then chosen as the operating frequency.

The variable $\left|T_{n}\right|$ is useful for predicting the radiation property of EBG antennas. The frequency $f_{0}$, the bandgap and the passband positions depend on the geometrical parameters of the EBG structure: 


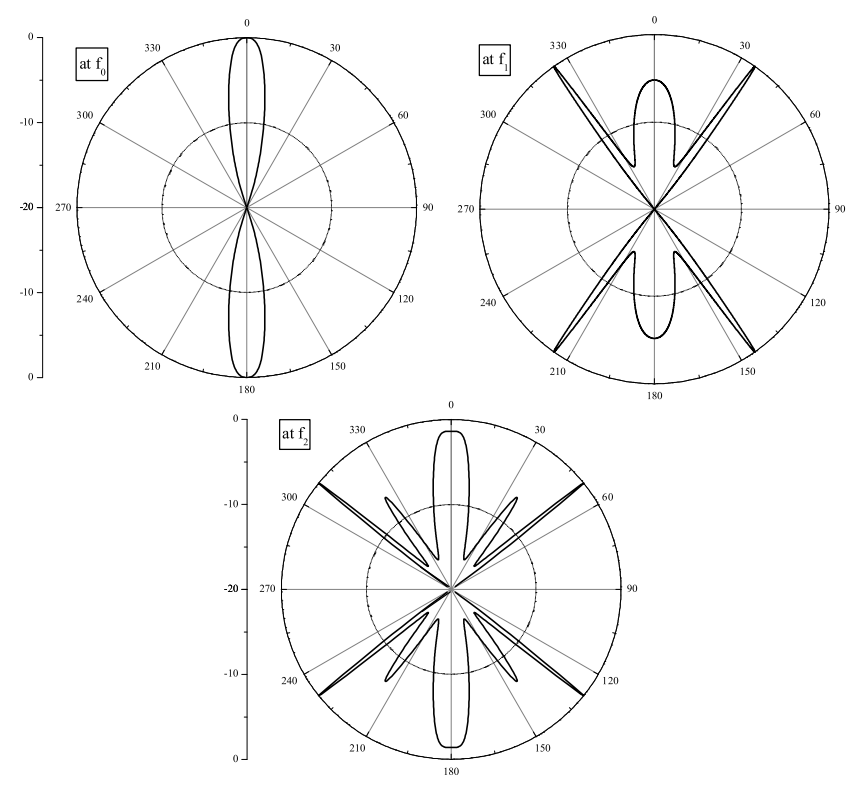

Figure 10. Normalized $\left|T_{3}\right|$ versus $\theta$ at $f_{0}, f_{1}$ and $f_{2}$.

wire diameter and periods between wires and surfaces. The proposed method can be used to match the operating frequency and the pattern shapes. Compared to structures composed of only one PRS on each side of the source, structures with multiple PRSs give more design parameters. The method can also be used for structures with different periods between PRSs and/or different PRSs, in order to investigate antennas producing multiple frequency operation or with larger bandwidth.

\section{ANTENNA DESIGN}

In this section, the previous theoretical investigations are applied to the design of a high-gain EBG antenna. The antenna, shown in Fig. 11 , is composed of a monopole as an excitation source, a ground plane, the crystal of metallic wires studied in the previous section (see Fig. 3 ), and four metallic planes : one on the top and three on the lateral sides. These metallic reflectors allow to focalize the radiation forward one side. 
FDTD simulations were carried out to match the positions of the metallic reflectors so the antenna performance would not be affected. To validate the proposed concept, an EBG antenna prototype was fabricated and tested. Figure 12 shows a photograph of the fabricated antenna.

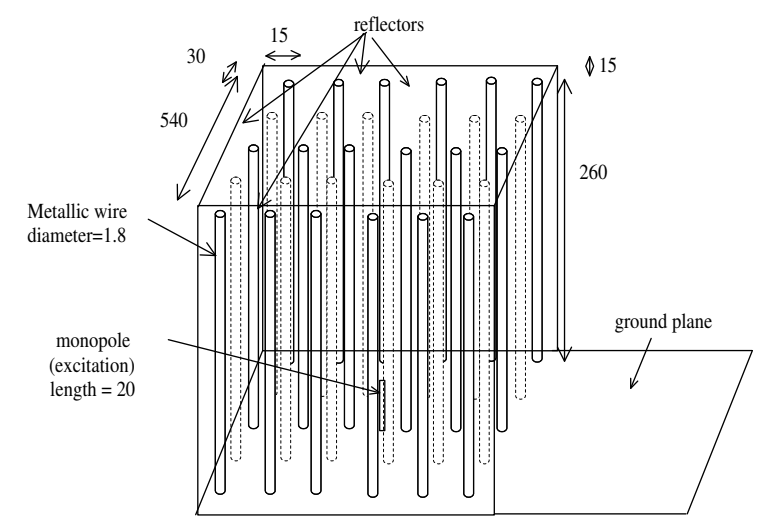

Figure 11. Geometry of the EBG antenna with reflectors (dimensions in $\mathrm{mm})$.

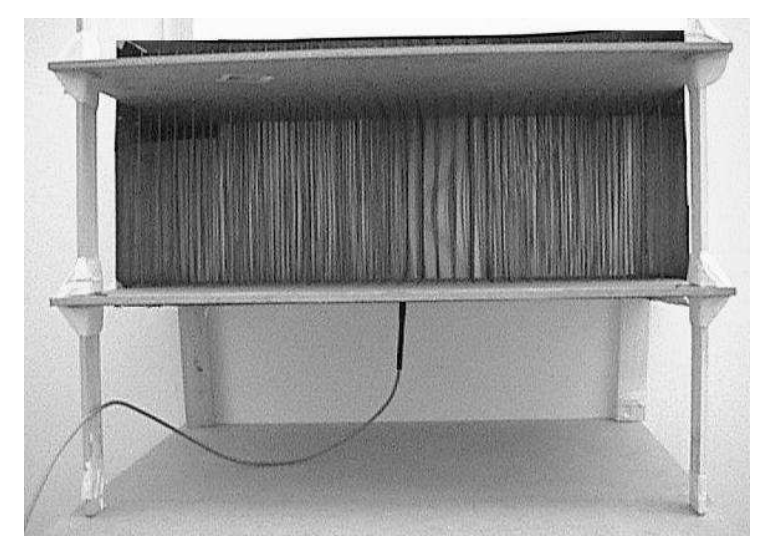

Figure 12. Photograph of the fabricated EBG antenna.

Figure 13 presents simulated and measured return loss of the proposed antenna. A slight difference between the simulation and measurement results is noted, and this is most likely due to the finite dimensions of 
the ground plane of the experimental prototype. From the measured return loss, a bandwidth $\left(S_{11}<-10 \mathrm{~dB}\right)$ from $2.61 \mathrm{GHz}$ to $2.65 \mathrm{GHz}$ (a fractional bandwidth of $1.5 \%$ ) is achieved.

To examine the radiation performance of the fabricated prototype, measurements were done using an anechoic chamber and a hybrid nearfield system from ANTCOM (http://www.antcom.com). Figure 14 shows the measured and simulated radiation patterns of the antenna at the center frequency $2.63 \mathrm{GHz}$ in the H-plane and E-plane. There is a slight difference between measured and simulated results in the E-plane, which is due to effects from the edge of the ground plane that were not included in the FDTD model. The half-power beamwidths are $15.3^{\circ}$ and $23.1^{\circ}$ in the $\mathrm{H}$-plane and the E-plane, respectively. The measured directive gains are between $19 \mathrm{dBi}$ (at $2.61 \mathrm{GHz}$ ) and 20.2 $d B i$ (at $2.65 G H z)$. The X-pol level is about $-20 d B$.

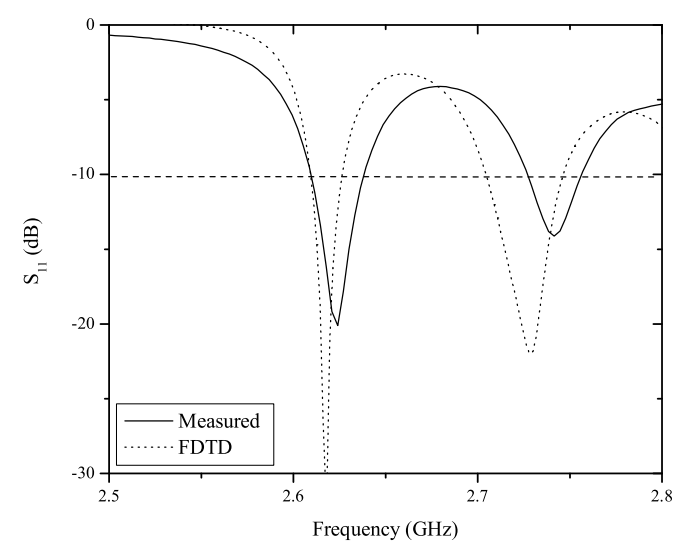

Figure 13. Measured return loss of the proposed EBG antenna.

To evaluate the performance of the antenna, the antenna aperture taper efficiency was calculated using the following equation [29]

$$
e=\text { Directivity } /\left(10 \log \left(4 \pi A / \lambda^{2}\right)\right),
$$

where $A=0.600 \times 0.275 \mathrm{~m}^{2}$ is the area occupied by the antenna in the $y z$ plane. The antenna taper aperture efficiency is between $89.4 \%$ (at $2.61 \mathrm{GHz}$ ) and $94.4 \%$ (at $2.65 \mathrm{GHz}$ ). With such features, this antennas is suitable for wireless communication systems, where high gain is needed. 


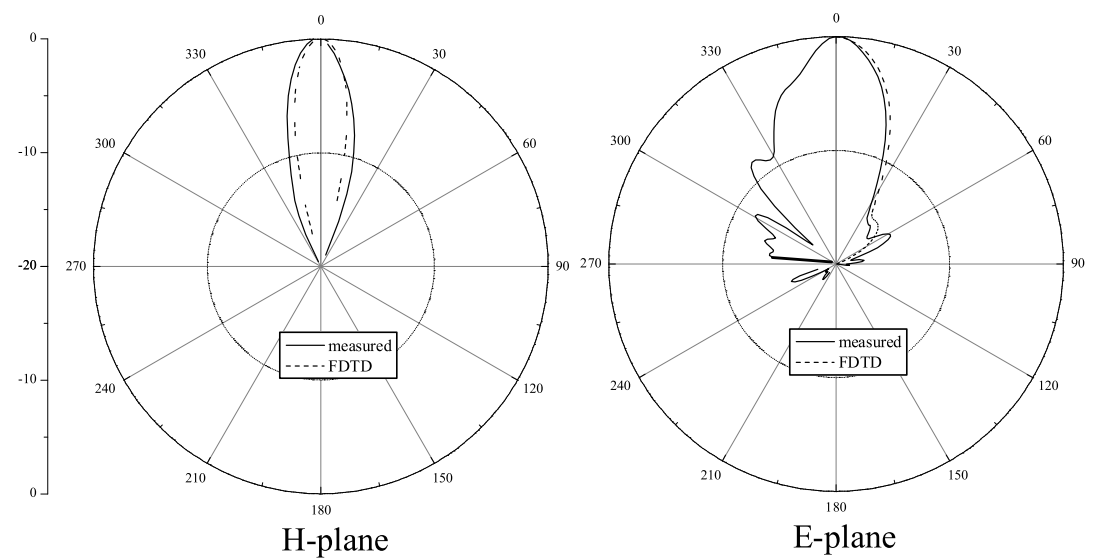

Figure 14. Measured and simulated co-pol radiation patterns in the $\mathrm{H}$-plane and E-plane at 2.63 $\mathrm{GHz}$.

\section{CONCLUSION}

A new high-gain antenna has been developed from a crystal without defect and constituted of metallic wires. A technique for characterizing the EBG structure excited from its interior has been described, and numerical and experimental results of the proposed antenna have been presented with a good agreement. A gain of more than $19 \mathrm{~dB} i$ has been obtained across the matching band of the antenna, at the lower end of pass-band of the EBG material. The proposed EBG antenna has the advantages in terms of high gain and simple single feed, which can reduce complexity compared to feeding networks used in conventional antenna arrays. Future work will concentrate on the examination of other structures using different distances between PRSs or/and different PRSs in order to increase the bandwidth of the antenna or to obtain multi-band antennas. 


\section{REFERENCES}

1. Joannopoulos, J., Meade, R. D., and Winn, J. N., Photonic crystals: molding the flow of light, Princeton University Press, 1995.

2. Park, Y.-J., Herchlein, A., and Wiesbeck, W., "A Photonic Bandgap (PBG) structure for guiding and suppressing surface waves in millimeter-wave antennas", IEEE Trans. Antennas Propagat., vol. 49, pp. 1854-1857, Oct. 2001.

3. Yang, F., and Rahmat-Samii, Y. "Microstrip antennas integrated with electromagnetic bandgap (EBG) structures: a low mutual coupling design for array applications", IEEE Trans. Antennas Propagat., vol. 51, pp. 2936-2946, Oct. 2003.

4. Lourtioz, J.M., De Lustrac, A., Gadot, F., Rowson, S., Chelnokov, A., Brillat, T., Ammouche, A., Danglot, J., Vanbesien, O. and Lippens, D., "Toward controllable photonic crystals for centimeter and millimeter wave devices", J. Lightwave Tech., vol. 17, pp. 2025-2031, Nov. 1999.

5. Poilasne, G., Pouliquen, P., Mahdjoubi, K., Desclos, L., and Terret, C., : "Active metallic photonic bandgap material MPBG: experimental results on beam shaper", IEEE Trans. Antennas Propagat., vol. 48, pp. 117-119, Jan. 2000.

6. Akalin, T., Danglot, J., Vanbesien, O., and Lippens, D., "A highly directive dipole antenna embedded in a Fabry-Perot type cavity", IEEE Microwave Wireless Comp. Lett., vol. 12, pp. 48-50, Feb. 2002.

7. Biswas, R., Ozbay, E., Temelkuran, B., Bayandir, M., Sigalas, M., and Ho, K.-M., "Exceptionally directional sources with Photonic Band-Gap crystals", J. Opt. Soc. Amer., vol. 18, no. 11, pp. 16841689, Nov. 2001.

8. Boutayeb, H., Mahdjoubi, K., Tarot, A.C., and Denidni, T.A. "Directivity of an antenna embedded inside a Fabry-Perot cavity : Theory and Design", Microw. Opt. Technol. Lett., to appear in Jan. 2006.

9. Thevenot, M., Cheype, C., Reineix, A., and Jecko, B., "Directive Photonic Band-Gap antennas", IEEE Trans. Microwave Theory Tech., vol. 47, pp. 2115-2122, Nov. 1999.

10. Cheype, C., Serier, C., Thevenot, M., Monediere, T., Reineix, A., and Jecko, B., "An Electromagnetic Bandgap resonator antenna", IEEE Trans. Antennas Propagat., vol. 50, pp. 1285-1290, Sept. 2002.

11. Yang, H. Y. and Alexopoulos, N. G., "Gain enhancement methods 
for printed circuit antennas", IEEE Trans. Antennas Propagat., vol. 35, pp. 860-863, July 1987.

12. Jackson D.R., and Oliner, A. A., "A leaky wave analysis of the high gain printed antenna configuration", IEEE Trans. Antennas Propagat., vol. 36, pp. 905-910, July 1988.

13. Jackson D.R., and Oliner, A. A., and Ip, A., "Leaky wave propagation and radiation for a narrow beam multiple layer dielectric structure", IEEE Trans. Antennas Propagat., vol. 41, pp.341-348, Mar. 1993.

14. Zhao, T., Jackson, D.R., Williams, J.T., and Oliner, A. A., "Simple CAD model for a dielectric leaky wave antenna", IEEE Trans. Antennas Propagat., vol. 41, pp.341-348, Mar. 1993.

15. Bulu, I., Caglayan, H., and Ozbay, E., "Highly directive radiation from sources embedded inside photonic crystals", App. Phys. Lett., vol. 83, no. 16, pp. 3263-3265, Oct. 2003.

16. Enoch, S., Tayeb, G., Sabouroux, P., Guerin, N., and Vincent, P., "A metamaterial for directive emission", Phys. Rev. Lett., vol. 89, no. 21, pp. 213902-1-213902-4, Nov. 2002.

17. Boutayeb, H., Mahdjoubi, K., and Tarot, A.C., "Design of a directive and matched antenna with a planar EBG structure", in IEEE APS Int. Symp. Dig., vol. 1, 2004, pp. 835-838.

18. Trentini, G.V., "Partially reflecting sheet arrays", IRE Trans. Antennas Propagat., vol. 4, pp. 666-671, Oct. 1956.

19. Feresidis A.P., and Vardaxoglou, J.C., "High gain planar antenna using optimized partially reflective surfaces", IEE Proc. Microwave Antennas Propagat., vol. 148, pp. 345-350, Dec. 2001.

20. James, J.R., Kinany, S. J. A., Peel, P. D., and Andrasic, G., "Leaky-wave multiple dichroic beamformers", Electron. Lett., vol. 25, pp. 1209-1211, Aug. 1989.

21. Felbacq, D., Tayeb, G., and Maystre, D., "Scattering by a random set of parallel cylinders", J. Opt. Soc. Am. A, vol. 11, pp. 25262538, Sept. 1994.

22. Hall, R.C., Mittra, R., and Mitzner, K.M., "Analysis of multilayered periodic structures using generalized scattering matrix", IEEE Trans. Antennas Propag., vol. 36, pp. 111-117, Apr. 1988.

23. Munk, B. A., Frequency Selective Surfaces: Theory and Design, Wiley-Interscience Publication, 2000.

24. Ansoft Corporation, High Frequency Structure Similator 8.5 User manual, Pittsburg, PA, 2001.

25. Hecht, E., Optics, Addison Wesley, San Francisco, CA, 2002, 421- 
425 .

26. de C. Lima, A.C., and Parker, E.A., "Fabry-Perot approach to the design of double layer FSS", IEE Proc. Microwave Antennas Propagat., vol. 143, pp. 157-162, Apr. 1996.

27. Berenger, J.-P., "Perfectly matched layer for the FDTD solution of wave-structure interaction problems" IEEE Trans. Antennas Propagat., vol. 44, no. 1, pp.110 - 117, Jan. 1996.

28. Nadobny, J., Pontalti, R., Sullivan, D., Wlodarczyk, W., Vaccari, A., Deuflhard, P., and Wust, P., "A thin-rod approximation for the improved modeling of bare and insulated cylindrical antennas using the FDTD method", IEEE Trans. Antennas Propagat., vol 51, pp. 1780-1796, Aug. 2003.

29. Stutzman, W. L., and Thiele, G. A., Antenna theory and design, second Ed., John Wiley and Sons, p. 295, 1998.

Halim Boutayeb was graduated in 2000 from the "Institut de Formation Supérieure en Informatique et Communication" (IFSIC) Rennes, France, in signal processing and telecommunications. He received the French D.E.A. degree (Master) in electronics in 2000 and the Ph.D in signal processing and telecommunications from the University of Rennes in 2003. He received the Best Paper Award at the JINA international conference in antenna in November 2004. Since March 2004, he is a contracted Researcher with INRS-EMT, Montreal, Canada.

Tayeb A. Denidni received the B.Sc. degree in electronic engineering from the University of Setif, Algeria, in 1986, and the M. Sc. and Ph.D. degrees in electrical engineering from Laval University, Quebec City, QC, Canada, in 1990 and 1994, respectively. From 1994 to 2000, he was an Assistant Professor with the engineering department, Universit du Quebec in Rimouski (UQAR), in Canada, where he founded the Telecommunications laboratory. Since August 2000, he is with the Personal Communications Staff, Institut National de la Recherche Scientifique (INRS)-EMT, University of Quebec, Montreal, Canada, where he founded the RF laboratory. 